\title{
Scale Analysis of Blocking Events from 2002 to 2004: A Case Study of an Unusually Persistent Blocking Event Leading to a Heat Wave in the Gulf of Alaska during August 2004
}

\author{
H. Athar' and Anthony R. Lupo ${ }^{2}$ \\ ${ }^{1}$ Center of Excellence for Climate Change Research, King Abdulaziz University, P.O. Box 80208, Jeddah 21589, Saudi Arabia \\ ${ }^{2}$ Department of Soil, Environmental and Atmospheric Sciences, 302 ABNR Building, University of Missouri, Columbia, \\ MO 65211, USA
}

Correspondence should be addressed to H. Athar, ahussain1@kau.edu.sa

Received 19 February 2010; Revised 14 May 2010; Accepted 28 June 2010

Academic Editor: Luis Gimeno

Copyright ( $) 2010$ H. Athar and A. R. Lupo. This is an open access article distributed under the Creative Commons Attribution License, which permits unrestricted use, distribution, and reproduction in any medium, provided the original work is properly cited.

\begin{abstract}
The climatology of northern hemisphere blocking events is presented assessing the relative contributions of the planetary and synoptic scales to $500 \mathrm{hPa}$ heights in order to determine the proportion of blocks dominated by a single-scale. The heights were averaged over a region encompassing the block, and then compared with corresponding monthly mean values. If planetaryscale or synoptic-scale heights are greater than the monthly mean, the block is called single-scale dominant. In the study, $79 \%$ of blocks were single-scale dominant, whereas the remaining $21 \%$ of events were alternating-scale prominent. This proportion varied by season with winter (summer) events being synoptic (planetary) scale dominant. The stability of blocks is also examined to determine if two stability indicators were useful in the assessment of the character of planetary and synoptic-scale flows. These quantities are area integrated enstrophy, and the maximum value of stream function gradients within the block region. The analysis of a prolonged block occurring in the Gulf of Alaska during August 2004 shows the planetary-scale is unstable during block onset and then stabilizes during the mature stage. The synoptic-scale played a dominant role in destabilizing the planetary-scale during the mature stage of the block initiating decay.
\end{abstract}

\section{Introduction}

The development of a predominantly mid-tropospheric, meridional circulation pattern within a sector of the northern or southern hemisphere is commonly referred to as blocking (e.g., $[1,2])$. This stagnation of the zonal flow gives rise to difficulties in operational weather forecasts for regions within and near the blocked region (e.g., $[3,4])$. Developing an understanding of the processes that leads to the formation of such circulation patterns is thus of significant interest.

The Charney and DeVore model provides a framework for incorporating the low frequency (planetary-scale) dynamics into the quasigeostrophic barotropic vorticity equation in order to obtain the blocking patterns for the given forcings using the concept of stable equilibria [5]. The Shutts model, on the other hand, provides a framework to incorporate the high-frequency (synoptic-scale) dynamics into the quasigeostropic barotropic vorticity equation to obtain the blocking events for prescribed forcings [6]. Both models offer numerical solutions of the nonlinear barotropic vorticity equation. Other studies include both scales in their modeled analysis of the blocking events $[7,8]$.

From a synoptic-dynamic point of view, and making use of surface and upper air data provided by reanalyses, numerous case studies have been carried out leading to valuable insight into the forcing mechanisms that may be important during various stages of the blocking (e.g.) [917]). In several of these case studies, the question of the role of planetary-scale versus synoptic-scale processes during the various stages of the blocking life-cycle is addressed.

In recent years, several studies also have examined the relative role of each scale and their interactions as well as the 
nature of the interactions themselves (e.g., $[9,18,19]$, and references cited therein). In addition to these studies, and those of earlier pioneers (e.g., [20-23]), a consistent picture emerges that the synoptic-scale plays an important role in the life-cycle of the blocking events. These studies show that the magnitude of the synoptic-scale forcing is generally large as compared to the planetary-scale forcing.

While the studies referenced in the above paragraph do not downplay the role of the planetary-scale, they do focus more on the role of the synoptic-scale contributions. However, others have shown that the planetary-scale is very influential in the life-cycle of the blocking events (e.g., [2427]). For instance, in their model study, [24] suggested that the blocking regimes will break down when there is a substantial change in the planetary-scale flow regime. Then, [25] focus on the role of the planetary-scale deformation in a preconditioned environment during the formation of the blocking events (see also [28]). These two studies together support the notion that while the planetary-scale may not itself lead to the block formation and maintenance, nevertheless this scale may provide a favorable environment in the interaction with the synoptic-scale environment. Thus, a substantial change in the planetary-scale flow regime may not support blocking and these events would decay fairly quickly.

In this paper, the scale characteristics of all the midlatitude blocking events occurring in the northern hemisphere (NH) during the three-year period 2002-2004 are examined in order to assess the relative role of the synoptic- and planetary-scales. We present a detailed characterization of the blocking events during the above three-year period based on the relative role of planetary-scale and/or synopticscale contributions. The aim is to provide a reference document that may be used to select suitable blocking events as examples for the three classes of the quasigeostrophic barotropic vorticity equation solutions mentioned earlier in this section.

It is further pointed out that abrupt changes in the planetary-scale environment can lead to the onset or decay of the blocking. In order to accomplish this, we will look at the area integrated regional enstrophy and maximum of the absolute value of geostrophic stream function gradient, as diagnostic tools in a selected blocking case study. These are then calculated using both the planetary- and synopticscale components of the flow. These indicators of stability were originally developed by $[29,30]$, and will be applied, to our knowledge, for the first time, to a NH case study. Also, the time evolution of the planetary/synoptic-scale height and of the stability indicators will be studied. In contrast to many previous studies mentioned in this section, we concentrate on examining the relative role of both the planetary- and synoptic- scales (and determining the flow stability).

The paper outline is as follows. In Section 2, we present the details of the data set used and describe the methodologies, including the stability indicators. In Section 3, we elaborate the results of the predominance of synoptic- versus planetary-scale contributions analysis performed for all the midlatitude blocking events occurring during the three-year period (2002-2004) in the NH. As a representative case study, the details of the synoptic and the stability analyses of a selected blocking event are presented in Section 4. The emphasis in this case study is on the relative role of the planetary- and synoptic-scales to quantify the flow stability. A summary of the three-year study and the results for the case study are presented in Section 5.

\section{Data and Methods}

2.1. Data Set. The data set used here was the National Center for Environmental Prediction (NCEP) and National Center for Atmospheric Research (NCAR) gridded reanalyses data $[31,32]$. These data were provided on the $2.5^{\circ}$ by $2.5^{\circ}$ latitude-longitude grids available on 17 mandatory levels from $1000 \mathrm{hPa}$ to $10 \mathrm{hPa}$ at 6 -h intervals on daily basis. A three-year period leading up to the year the case study occurred was examined.

2.2. Blocking Definition. The blocking criterion of [33] will be used to determine the onset and termination times for the blocking events studied. The blocking events may be subdivided into onset, intensification, maintenance, and decay stages (e.g., $[12,14,15])$. Onset is the period before the block formation, while intensification (decay) is represented by a general increase (decrease) in center point heights. Maintenance is generally represented by periods where the center point time evolution is close to zero. In brief, these studies employ a combined and extended set of conditions set forth earlier by the subjective definition of $[1,2]$, and the objective criterion of Lejenas and Okland [34].

The $500 \mathrm{hPa}$ height at 1200 UTC is used as a diagnostic atmospheric variable. Briefly, the blocking detection criterion includes: (i) satisfying the $\operatorname{Rex}[1,2]$ criteria for the blocking with the minimum duration of the blocking as 5 days; (ii) a negative or small positive LO 83 index [34], must be present on a time-longitude or Hovmöller diagram; (iii) conditions (i) and (ii) satisfied for $24 \mathrm{~h}$ after onset to $24 \mathrm{~h}$ before termination; (iv) the blocking should be pole ward of $35^{\circ} \mathrm{N}$, and the ridge should have an amplitude of greater than $5^{\circ}$ latitude; and (v) blocking onset is described to occur when condition (iv) and either conditions (i) or (ii) are satisfied, (v) termination is designated at the time the event fails condition ( $\mathrm{v}$ ) for a $24 \mathrm{~h}$ period or longer. This procedure is used to detect the blocking events at $500 \mathrm{hPa}$ and defines the blocking duration with start and end dates.

The blocking intensity (BI) is defined as [33]

$$
\mathrm{BI}=100[(Z \max / Z)-1] .
$$

In (1), $Z$ max is the maximum $500 \mathrm{hPa}$ height in the closed anticyclone region or on a line associated with the ridge, and $Z$ is the subjectively chosen $500 \mathrm{hPa}$ height contour encompassing the upstream and downstream troughs. The BI measures the amplitude of the flow around the block. For further details and examples, the reader is referred to [33].

As mentioned before, this study will point out that changes in the planetary-scale and synoptic-scale flow regimes can be related to the onset and the decay of the blocking events. The techniques used to extract planetary- 
and synoptic-scale heights have been used in many of the previous studies $[11,12,14]$, and will be only briefly presented.

A second-order, two-dimensional filter was used on the reanalysis heights in order to separate the planetary-scale heights $\left(Z_{p}\right)$ from the observed $500 \mathrm{hPa}$ height value $(Z)$ [35]. The filter performs a center weighted symmetric finite element calculation in spatial dimensions. The filtered data retain $2 \%, 44 \%$, and $80 \%$ of the original signal at wavelengths of $3000 \mathrm{~km}, 4500 \mathrm{~km}$, and $6000 \mathrm{~km}$ at $45^{\circ} \mathrm{N}$. The synopticscale heights $\left(Z_{s}\right)$ were obtained using $Z_{s}=Z-Z_{p}$. More details regarding the use of the filtering procedure can be found in [11].

Then, the planetary-scale height fields were averaged over $40^{\circ}$ latitude by $60^{\circ}$ longitude box within the blocking sector to produce one number for each block detection. This process is analogous to the procedure used by [36] in deriving the wave amplitude index, with the exception that we filtered the fields first and then averaged them within a box. They averaged the entire midlatitude height field into a band and then filtered to obtain a single number for the time period for the $\mathrm{NH}$.

2.3. Blocking Area Integrated Regional Enstrophy. In [29], blocking was defined as a meridional perturbation that destabilizes the zonal flow. Starting from the barotropic vorticity equation, the blocking area integrated enstrophy is suggested as a measure for the change in the zonal flow that may lead to the blocking. Here, we make use of the conjecture in [29] which suggests a relationship between the sum of the positive eigenvalues of the linearization operator of the barotropic flow and the blocking domain integrated regional enstrophy, that is,

$$
\sum_{i} \lambda_{i}^{+} \approx \int_{D}|\varsigma|^{2}(y) d x d y,
$$

where $\varsigma=-\partial u / \partial y$ and $D$ is the blocking domain. A brief discussion of how to obtain (2) is provided in Appendix A, following [29]. The blocking domain $D$ is defined as a latitude and longitude box as mentioned above. We will call the right hand side of (2) as the blocking area integrated regional enstrophy (IRE) here. We can regard the IRE as a stability indicator. This has not been used in the literature before as a blocking diagnostic for observed case studies, and (2) will be used to determine the relative stability of the flow in region $D$. Higher positive values of the IRE correspond to more unstable flow and vice versa. For a discussion of time evolution of the eigenmodes of the barotropic flow including the effect of $\beta$, see [37].

2.4. Maximum of the Absolute Value of the Stream Function Gradient. We have calculated numerically another indicator of flow regime stability following [30], that is, the maximum of absolute value of the gradient of the geosptrophic stream function $(\max |\nabla \psi|)$. Here

$$
\psi=\frac{g Z}{f}
$$

TABLE 1: Assessment of the blocking domain size variation, for the $500 \mathrm{hPa}$ monthly average planetary-scale height, during August 2004 , for the selected blocking event.

\begin{tabular}{lc}
\hline$D$ (latitude $\times$ longitude $)$ & $\begin{array}{l}\text { Monthly planetary-scale } \\
\text { height averaged over the } \\
\text { blocking domain } D(\mathrm{~m})\end{array}$ \\
\hline $40^{\circ} \times 60^{\circ}$ & 5773 \\
$50^{\circ} \times 70^{\circ}$ & 5768 \\
$60^{\circ} \times 80^{\circ}$ & 5757 \\
$70^{\circ} \times 90^{\circ}$ & 5743 \\
$80^{\circ} \times 100^{\circ}$ & 5728 \\
\hline
\end{tabular}

where $f=2 \Omega \sin (\phi)$ is the Coriolis parameter with latitude denoted by $\phi$. The variable $\Omega$ is the rotation speed of earth ( $\Omega$ is taken as $7.292 \times 10^{-5} \mathrm{rad} \mathrm{s}^{-1}$ ), and the acceleration due to the gravity is $g$. The $\psi$ is the total stream function, so the quantity represented by $\max |\nabla \psi|$ may also be referred as maximum geosptrophic wind speed. The maximum value of this quantity is taken within the blocking domain $D$ and is meant to reflect the meridional variations in the flow. The behavior of this indicator of stability may have a simple physical meaning. In the case of vanishing zonal flow, meridional variations will have the dominant contribution. It may thus acquire a relative maximum positive value during the blocking state. For more details, see [30].

2.5. The Effect of Domain Size Variation. The domain $D$ used in (2) is defined as the $40^{\circ}$ latitude by $60^{\circ}$ longitude box as mentioned in Section 2.3. The latitude span is $40^{\circ}$ which encompasses the latitudinal extent of the blocking event in the midlatitudes. The longitude is centered at the blocking onset center and depends on the longitude extent of the selected blocking event.

Enlarging the blocking area domain $D$ from $40^{\circ} \times 60^{\circ}$ does not lead to any sizable deviation in the planetaryscale height when averaged over it. A representative example is displayed in Table 1, where the impact of enlarging the blocking area domain $D$ is assessed for the $500 \mathrm{hPa}$ monthly average planetary-scale height for a selected blocking event, our case study. The blocking event occurred during 0528 August 2004 over $40^{\circ} \mathrm{N}-80^{\circ} \mathrm{N}$ and $160^{\circ} \mathrm{E}-260^{\circ} \mathrm{E}$. The Table 1 indicates that the maximum variation in the monthly average planetary-scale height value is less than $1 \%$ relative to $40^{\circ} \times 60^{\circ}$ box averaging value. Similar magnitude of variation relative to $40^{\circ} \times 60^{\circ}$ box averaging value was found when we varied the latitude only, the longitude only, and the selected blocking event, over the blocking domain $D$.

It is thus concluded that the blocking domain averaged results for planetary-scale height presented in this study are not sensitive to the choice of the size of the blocking domain $D$ within the range of latitude and longitude values specified in Table 1. The synoptic scale height, being a small-scale length is somewhat sensitive to the variations of the blocking domain $D$ (of the order of $15 \%-20 \%$ ). 


\section{Details of the Three-Year Study}

In this section, we first present the main characteristics and synoptic description of the blocking events for the three-year duration 2002-2004 and then the scale contribution characteristics of these events using the methodology presented in Section 2.

3.1. The Blocking Events during 2002-2004. The number of $\mathrm{NH}$ blocking events lasting 5 days or more during the threeyear period (2002-2004) under study are as follows: 2002 (41), 2003 (48), and 2004 (37). During this three-year period, the total number of blocking events is 126 . The highest number of blocking events occurred during the year 2003 (38\%). The detected blocking events during the above threeyear period are in line with the findings in [38].

The synoptic details of the blocking events during the three-year period in tabular form are presented in Appendix B. The blocking events' details include the start date, the end date, the duration, the BI as well as the geographic location. Table 2 summarizes the characteristics of the blocking events during the three-year period.

Table 2 indicates that, in general, the overall character of blocking events taken from this three-year period is similar to the climatologies of $[33,39]$ in that there were more winter season (Jan-Mar) events and more Atlantic region $\left(290^{\circ} \mathrm{E}-\right.$ $30^{\circ} \mathrm{E}$ ) events than in the other regions. Also, winter season events were, in general, stronger than those of summer season (Jul-Sep) events and oceanic region events were stronger than those found over the continents. Additionally, the events from this three-year period were more numerous, slightly weaker, and more persistent than those found in [39] which is consistent with the results of $[38,40]$.

During the three-year period (2002-2004), the longest duration (35 days) blocking event occurred over the continental area $\left(100^{\circ} \mathrm{W}-80^{\circ} \mathrm{W}\right.$ and $\left.40^{\circ} \mathrm{E}-140^{\circ} \mathrm{E}\right)$ during 4 June through 9 July, 2002, with BI $=1.99$ (weak event). It is event number 24 in Table 4. During the same three-year period, the strongest blocking event occurred over the Pacific area $\left(140^{\circ} \mathrm{E}-100^{\circ} \mathrm{W}\right)$, with $\mathrm{BI}=5.39$ with a duration of 6 days (19 March through 25 March 2003). It is event number 11 in Table 5.

The synoptic description of the blocking events displayed in Appendix B is used subsequently in this section to assess the behavior of the scale contributions and to perform the detailed stability analysis of a selected blocking event in the next section and this event is identified in italics.

\subsection{Scale Contribution Comparison for the Blocking Events} during 2002-2004. The longitude at block onset was obtained from the blocking event archive ([38], Appendix B). Then the blocking event box was formed relative to the blocking onset center location by adding $30^{\circ}$ in the east and the west directions. The latitude span was taken as $40^{\circ}$ centered at the midlatitude in accordance with discussion in Section 2 . The stationary $40^{\circ} \times 60^{\circ}$ latitude longitude box size selection is in line with the climatological $\mathrm{NH}$ spatial distribution of the blocking events [34]. It is also in line with the NH climatological track movement of the blocking events [41]. The results presented in Appendix B are sensitive to variations in domain size $D$ (see Section 2.5).

The filtered planetary-scale height was averaged over this latitude and longitude box. Next, the synoptic-scale height for each grid point of the domain was calculated following the procedure outlined in Section 2, and then averaged over the box. In the Appendix B, the entry labeled positive in the planetary-scale height column occurs if, at least, this height averaged over the mature stage of the blocking event is larger than the corresponding monthly mean height value. A similar definition was used for a positive entry in synoptic-scale column. If the blocking event fell within two months such as from 25 July through 15 August, the scale contribution dominance was determined by comparing the behavior of the averaged heights relative to the two month mean value.

The monthly mean was chosen simply to provide a zero reference point from which to assess which scale was prominent during the life-cycle of the event. There is no reason to assume $a$ priori that the size or sign of the monthly value for each scale would be related to whether or not a blocking event formed since the monthly mean would vary annually and would depend on where the box is located and the size of the box used. The block formation mechanisms also depend on the inter basin differences $[41,42]$.

Based on our above subjectively chosen criterion for comparison of heights, the blocking events are categorized into the following three types:

(i) planetary-scale height dominant events,

(ii) synoptic-scale height dominant events,

(iii) alternating-scale height dominant events.

In Section 4, a representative example of a blocking event with planetary-scale height dominant behavior (category (i)) is discussed in detail. Representative examples of category (ii) synoptic-scale height dominance, and (iii) alternating-scale height dominance, in which both the height scales dominate in a time series fashion, are described next in some detail in this section.

Figure 1 displays a single-scale contribution behavior case for a selected blocking event, corresponding to event number 8 in Table 6. This event occurred over the Atlantic with $\mathrm{BI}=4.62$, indicating that it is a strong event [39]. The event lasted for 5 days (15th March 2004 through 20th March 2004). The block longitude center at the onset was located at $0^{\circ} \mathrm{E}$. A single (synoptic)-scale dominance can be noted, during the mature stage, as the monthly mean value for synoptic-scale is $0.03361 \mathrm{~m}$, whereas the monthly mean value for the planetary-scale is $5633 \mathrm{~m}$ (compare with Figure 4).

Figure 2 displays an alternating-scale contribution behavior for a selected blocking event, corresponding to event number 3 in Table 4 . This event occurred over the Pacific with $\mathrm{BI}=4.50$, which is a strong event [39]. The event lasted for 21 days (07th January 2002 through 28th January 2002). The block longitude center at the onset was located at $250^{\circ} \mathrm{E}$. We note that in contrast to Figure 4, there is no single height dominance during the mature 
TABLE 2: A summary of the occurrence and character of the blocking events for the calendar years 2002-2004. Blocking parameters in each cell are blocking events/durations (days)/BI.

\begin{tabular}{lccccc}
\hline & Summer & Fall & Winter & Spring & Total \\
\hline Atlantic & $9 / 12.7 / 2.30$ & $17 / 10.7 / 3.27$ & $16 / 11.1 / 3.52$ & $16 / 10.0 / 2.78$ & $58 / 10.9 / 3.03$ \\
Pacific & $10 / 9.4 / 2.28$ & $7 / 10.6 / 3.36$ & $16 / 8.0 / 3.52$ & $9 / 11.6 / 2.65$ & $42 / 9.5 / 3.01$ \\
Continental & $10 / 12.9 / 2.18$ & $6 / 5.7 / 2.64$ & $4 / 8.4 / 2.88$ & $6 / 15.5 / 2.44$ & $26 / 11.1 / 2.46$ \\
\hline Total & $29 / 11.6 / 2.25$ & $30 / 9.7 / 3.16$ & $36 / 9.3 / 3.44$ & $31 / 11.5 / 2.67$ & $126 / 10.5 / 2.90$ \\
\hline
\end{tabular}

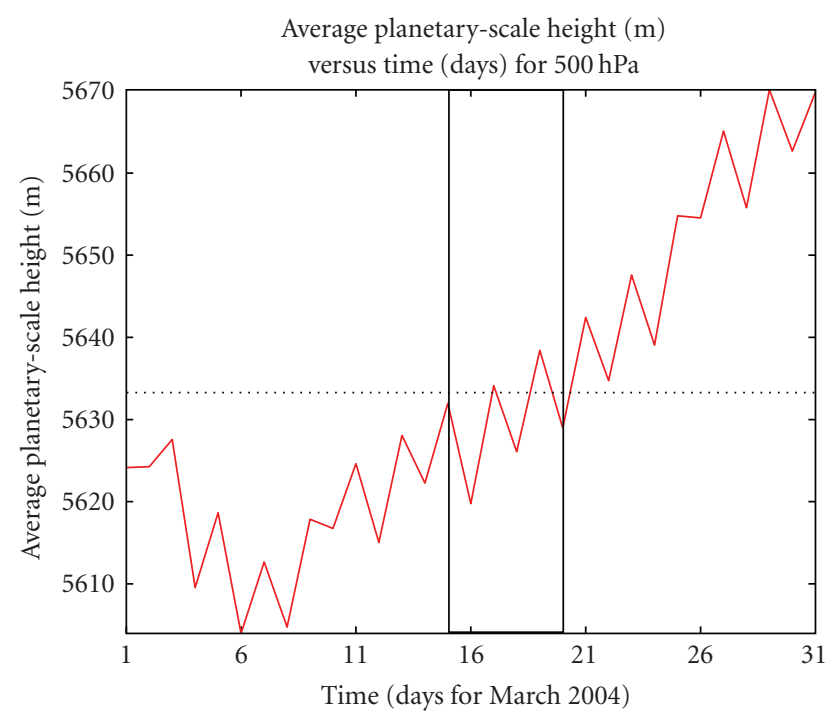

(a)

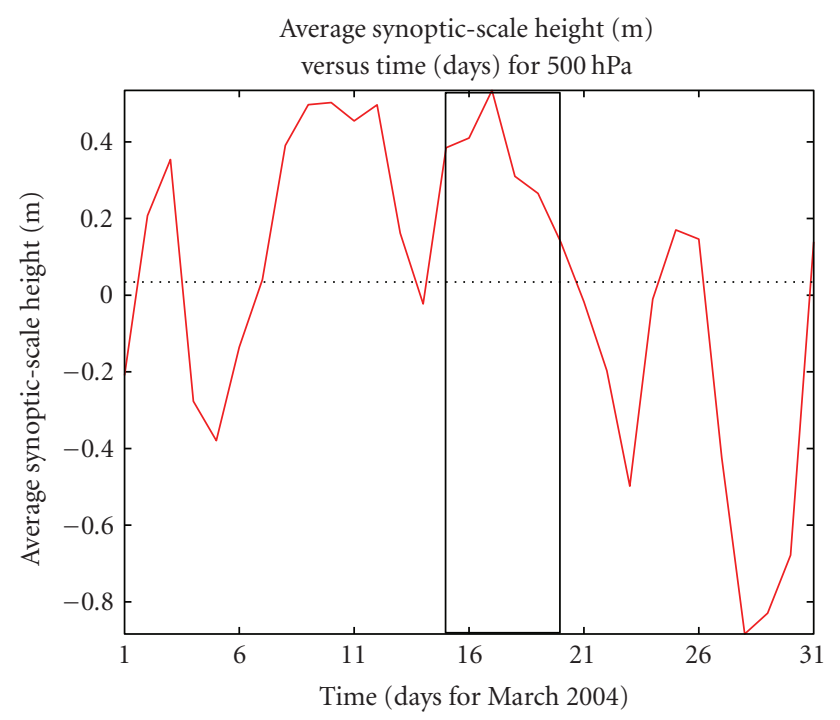

(b)

Figure 1: (a) The blocking area averaged planetary-scale $500 \mathrm{hPa}$ height $(\mathrm{m})$ versus time (days), for a stationary box $\left(20^{\circ} \mathrm{N}\right.$ to $60^{\circ} \mathrm{N}$ and $330^{\circ} \mathrm{E}$ to $30^{\circ} \mathrm{E}$ ), in the midlatitude northern hemispheric flow. The dashed dotted horizontal line defines the monthly mean value for the planetary-scale height. The left vertical line marks the beginning, whereas the right vertical line marks the end of the selected blocking event; (b) same as Figure 1(a) except for the synoptic-scale height.

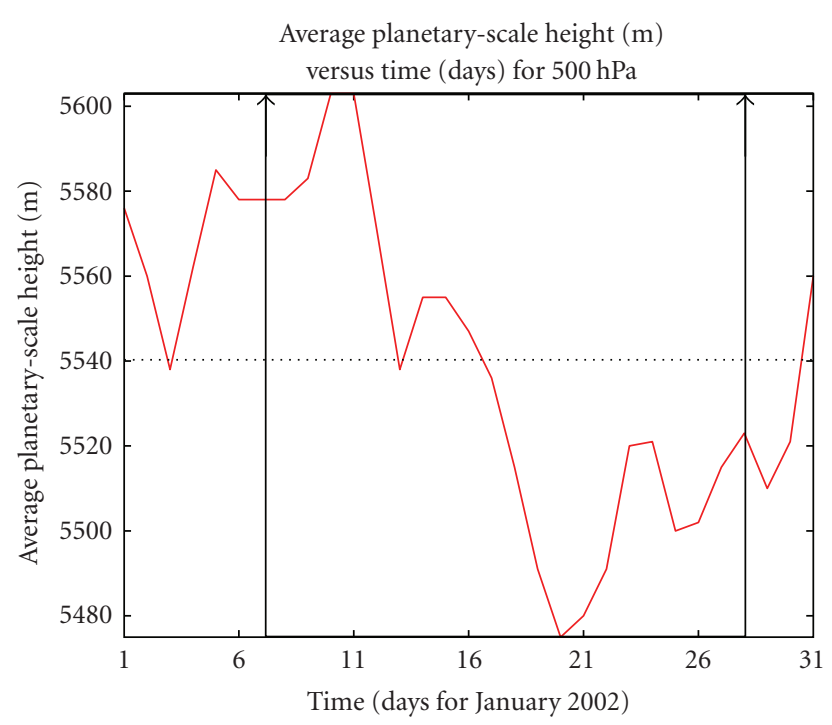

(a)

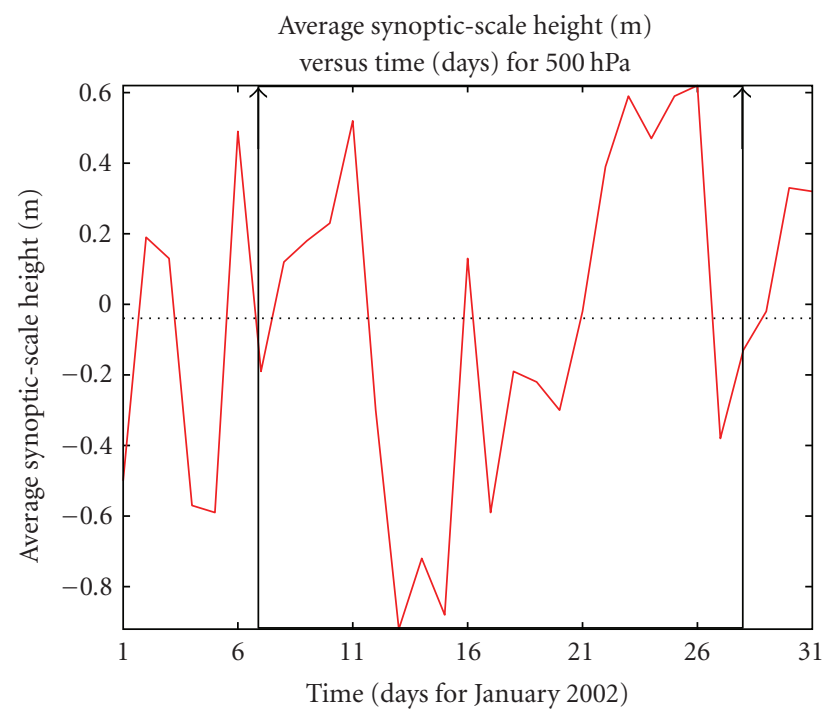

(b)

Figure 2: (a) The blocking area averaged planetary-scale $500 \mathrm{hPa}$ height $(\mathrm{m})$ versus time (days), for a stationary box $\left(20^{\circ} \mathrm{N}\right.$ to $60^{\circ} \mathrm{N}$ and $290^{\circ} \mathrm{E}$ to $230^{\circ} \mathrm{E}$ ), in the midlatitude northern hemispheric flow. The dashed dotted horizontal line defines the monthly mean value for the planetary-scale height. The left vertical upward arrow marks the beginning, whereas the right vertical upward arrow marks the end of the selected blocking event; (b) same as Figure 2(a) except for the synoptic-scale height. 


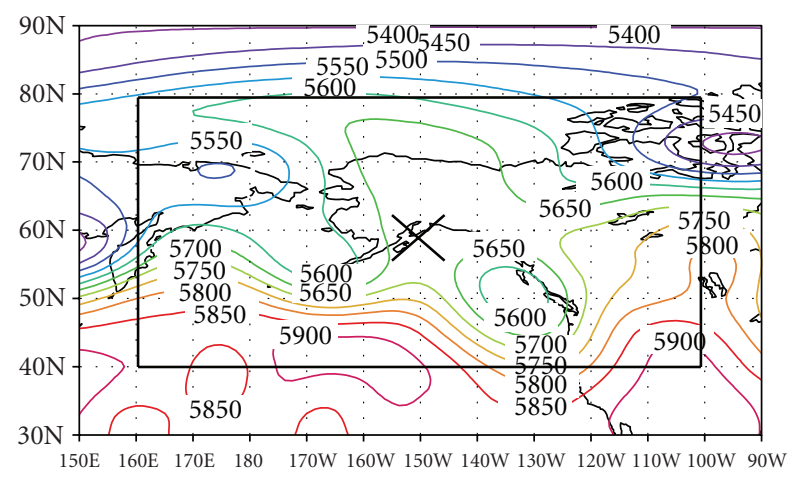

(a) 05 August 2004

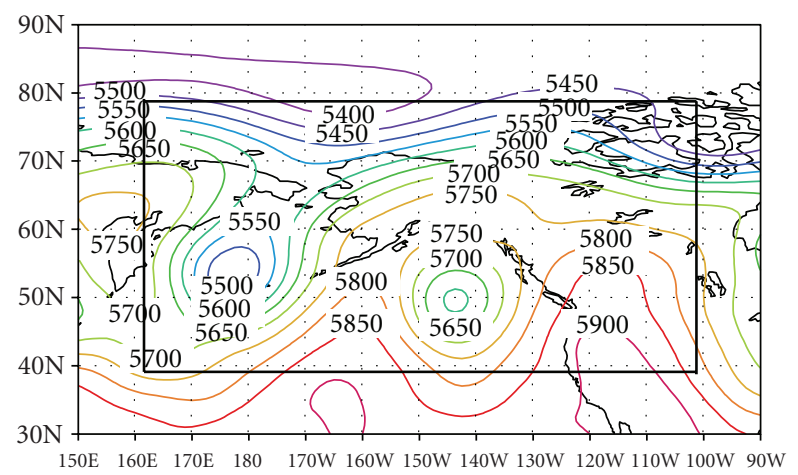

(b) 13 August 2004

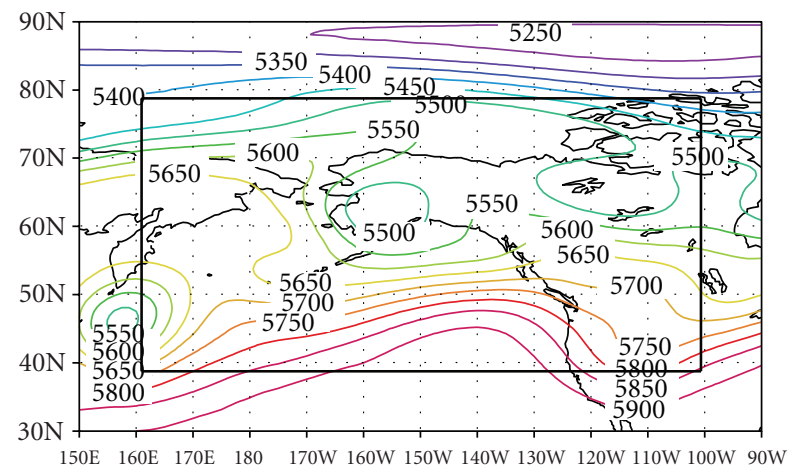

(c) 27 August 2004

Figure 3: (a) The $500 \mathrm{hPa}$ mean daily height. The cross indicates the center of blocking at the onset. The blocking domain boundary is marked around the center by thick solid black line. The continuous curves represent height contours at $50 \mathrm{~m}$ interval, for 05 August 2004. Note the meridional (split)-flow character of the block; (b) for 13 August 2004; (c) for 27 August 2004.

stage of the selected blocking event. Both the planetary- and synoptic-scale heights rise and fall occur during the life-cycle of the blocking event relative to their respective monthly mean values. The blocking events displaying this type of height-time evolution are categorized as the alternating-scale height dominance behavior blocking events. However, this category of the blocking events consists of only $21 \%$ of the total detected blocking events during the three-year period under study.

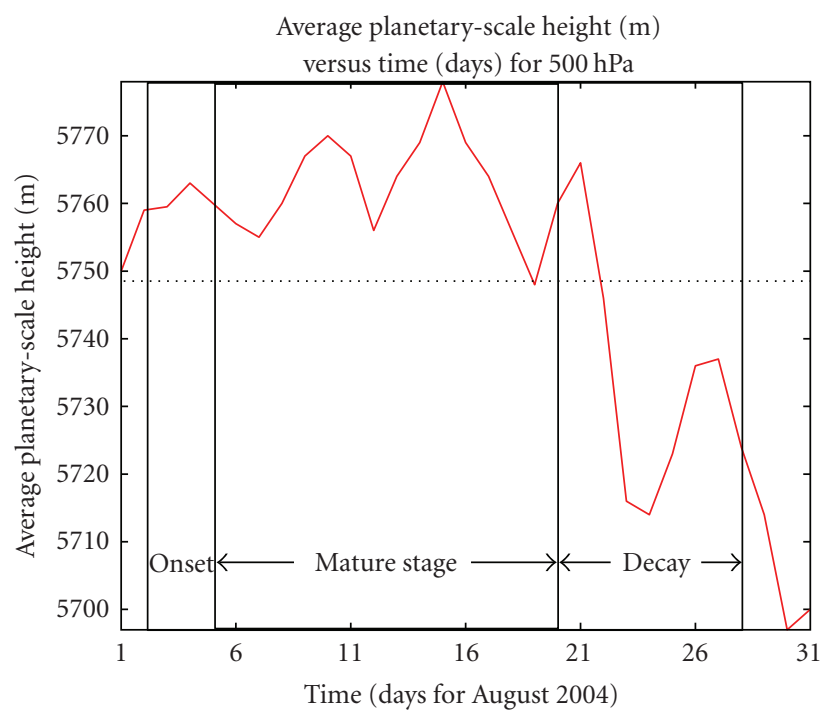

(a)

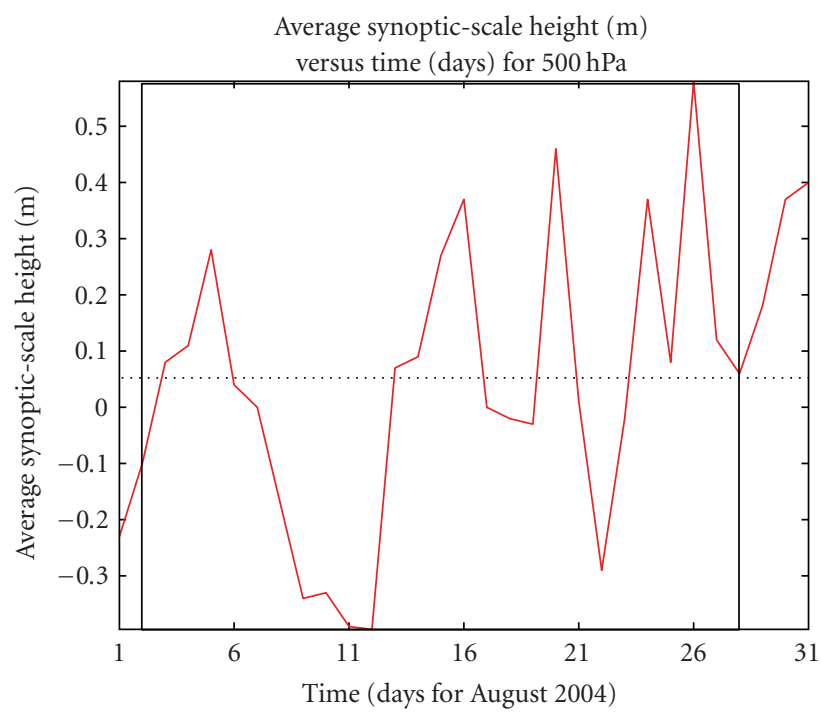

(b)

FIgURE 4: (a) The blocking area averaged planetary-scale $500 \mathrm{hPa}$ height $(\mathrm{m})$ versus time (days), for a stationary box $\left(40^{\circ} \mathrm{N}\right.$ to $80^{\circ} \mathrm{N}$ and $160^{\circ} \mathrm{E}$ to $260^{\circ} \mathrm{E}$ ), in the midlatitude northern hemispheric flow. The dashed dotted horizontal line defines the monthly mean value for the planetary-scale height. The left vertical line marks the beginning, whereas the right vertical line marks the end of the selected blocking event; (b) same as Figure 4a except for the synoptic-scale height.

3.3. Analysis Summary. Table 3 summarizes our findings for the blocking events with single and alternating-scale dominance for the three-year period over the entire $\mathrm{NH}$. The maximum (minimum) number of blocking event having planetary-scale dominance occurs during 2003 (2002) in NH. The minimum (maximum) number of blocking events having synoptic-scale dominance occurs during 2003 (2002). The seasonal results show that the winter and spring season events are more synoptic-scale dominant, while summer and fall events are strongly planetary-scale dominant. The 


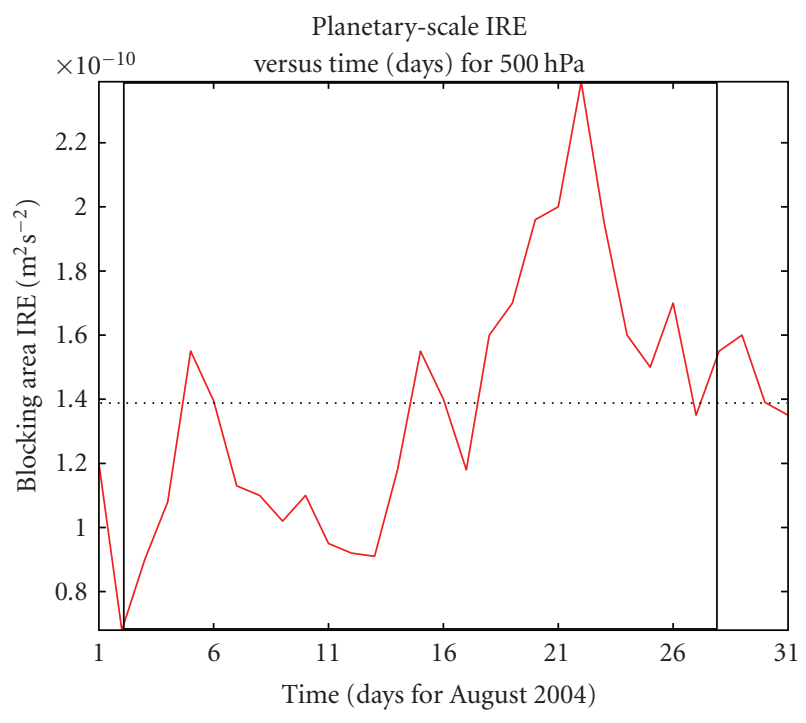

(a)

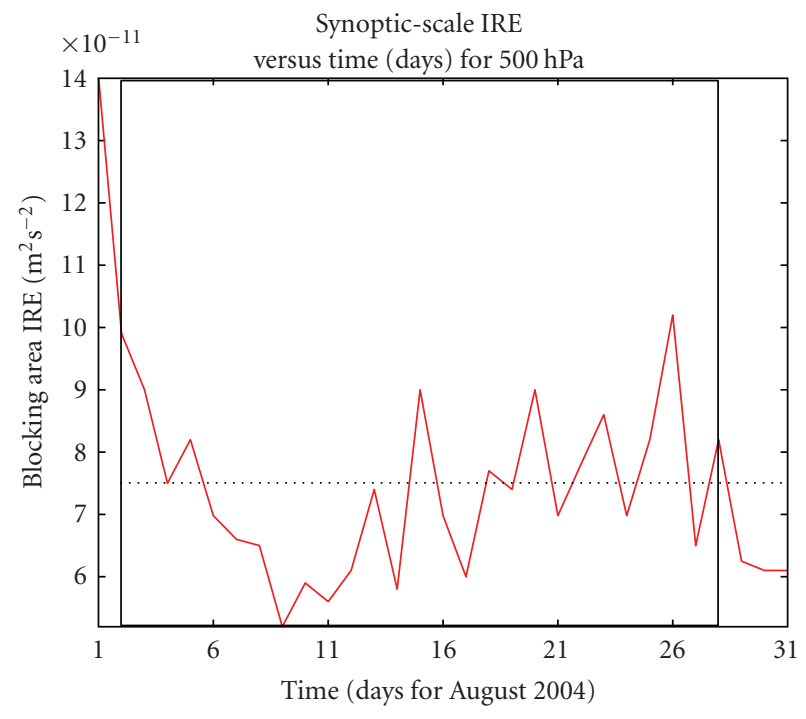

(b)

FIGURE 5: (a) The blocking area averaged enstrophy using (2) for the blocking event displayed in Figure 3 which occurred during 0528 August 2004. The relative stability level changes at onset (0205 August) and at decay (20-28 August) stages. The dash dotted horizontal line defines the monthly mean value. The left vertical line marks the beginning, whereas the right vertical line marks the end of the selected blocking event; (b) same as Figure 5(a) except for the synoptic-scale height.

seasonal variation of synoptic dominance is consistent with the seasonal variations in the number and strength of midlatitude cyclones (e.g., [43]). Table 3 is valid only for the blocking detection method, and scale categorization used in this study.

A prominent feature of our study is the finding that the scale contributions of a vast majority of the blocking events are governed by the dominance of the single-scale height scale. This category of blocking events thus constitutes a representative category of all the midlatitude blocking

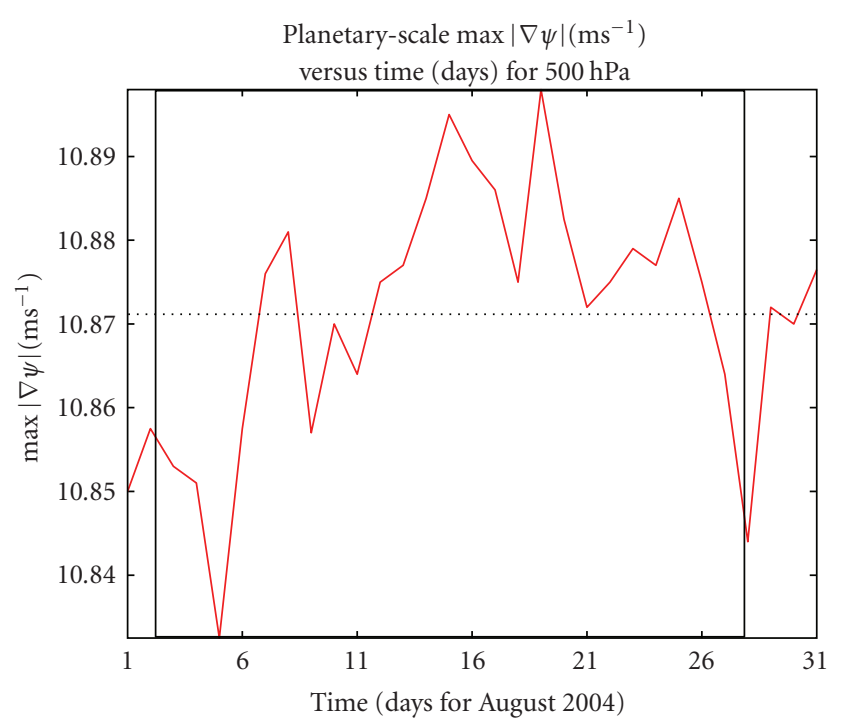

(a)

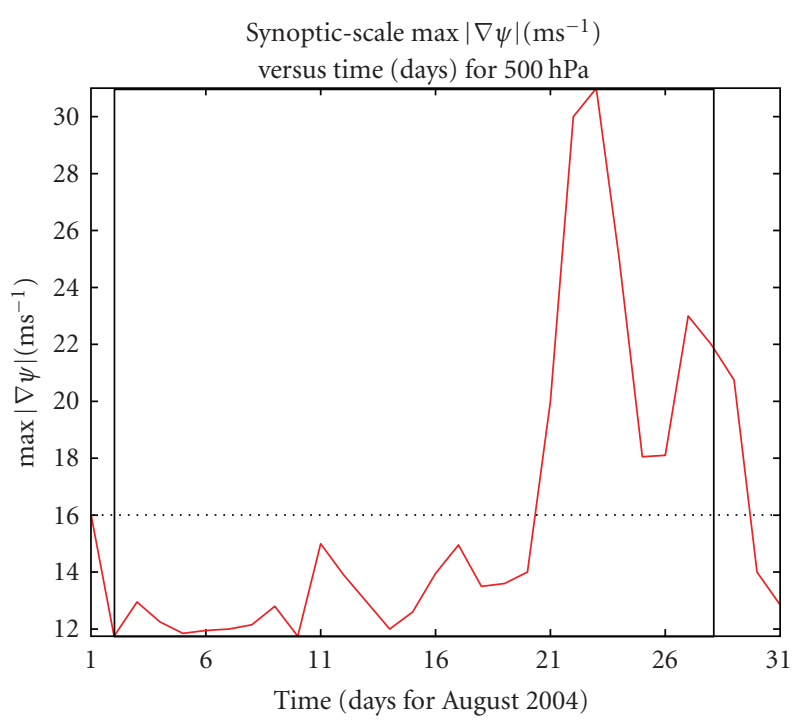

(b)

FIgURE 6: (a) The $500 \mathrm{hPa}$ planetary-scale $\max |\nabla \psi|$ versus time (days) for a stationary box $\left(40^{\circ} \mathrm{N}\right.$ to $80^{\circ} \mathrm{N}$ and $160^{\circ} \mathrm{E}$ to $\left.260^{\circ} \mathrm{E}\right)$ in the midlatitude northern hemispheric flow. The dash dotted line defines the mean monthly value for $\max |\nabla \psi|$. The left vertical line marks the beginning, whereas the right vertical line marks the end of the selected blocking event; (b) same as Figure 6(a) except that now the synoptic-scale effect is taken into account.

events occurring during the three-year study period. We thus perform next a detailed case study for the single-scale height dominance as a representative case study.

\section{Case Study}

In this section, detailed discussions of the synoptic aspects as well as the scale and the stability analysis of the flow for an unusually persistent blocking event that led to a heat wave in the Gulf of Alaska during August 2004 are presented [44]. 
TABle 3: Planetary-, synoptic-, and alternating-scale dominance results for the three-year period (2002-2004) analysis and for each season performed in this study, over the entire NH. The number and percentage for each year or season and the total is displayed.

(a)

\begin{tabular}{cccc}
\hline Year & Planetary & Synoptic & Alternating \\
\hline 2002 & $15 / 37 \%$ & $17 / 41 \%$ & $9 / 22 \%$ \\
2003 & $22 / 46 \%$ & $11 / 23 \%$ & $15 / 31 \%$ \\
2004 & $18 / 49 \%$ & $16 / 43 \%$ & $3 / 8 \%$ \\
\hline Total & $55 / 44 \%$ & $44 / 35 \%$ & $27 / 21 \%$ \\
\hline
\end{tabular}

(b)

\begin{tabular}{lccc}
\hline Season & Planetary & Synoptic & Alternating \\
\hline Winter & $12 / 33 \%$ & $17 / 48 \%$ & $7 / 19 \%$ \\
Spring & $12 / 39 \%$ & $14 / 45 \%$ & $5 / 16 \%$ \\
Summer & $16 / 55 \%$ & $6 / 21 \%$ & $7 / 24 \%$ \\
Fall & $15 / 50 \%$ & $7 / 23 \%$ & $8 / 27 \%$ \\
\hline
\end{tabular}

The synoptic analysis is performed first, and then a scale and stability analysis of the $\mathrm{NH}$ flow region where the selected blocking event occurred.

For the case study presented in the next section, a different latitude-longitude window is used to accommodate the unusually large spatial extent of the selected blocking event.

4.1. Synoptic Analysis. The selected blocking event occurred during 02 August through 28 August 2004. Following [33], the block onset and intensification stage was during 02-05 August, its mature stage was during 05-20 August and its decay stage was during 20-28 August. The blocking ridge lasted for 23.5 days. The blocking flow was located in the region encompassing $40^{\circ} \mathrm{N}$ to $80^{\circ} \mathrm{N}$ and $160^{\circ} \mathrm{E}$ to $260^{\circ} \mathrm{E}$, with block longitude at the onset was located at $210^{\circ} \mathrm{E}$. This is event number 26 in Table 6 in Appendix B. Above normal surface temperatures and below normal precipitation was reported during August over the entire Alaska region [44].

The height variations (taken at $500 \mathrm{hPa}$ ) that lead to identification of the blocking on an upper air chart can conveniently be quantified in terms of BI. According to the definition of BI [33], the BI for the considered blocking event averaged over its entire life-cycle is 2.44 , implying that it is a moderate strength blocking event.

Figure 3 indicates that during the block onset, a meridional (split)-flow pattern became prevalent in the $500 \mathrm{hPa}$ mean height field around the position marked with cross. In the Gulf of Alaska, a lower height value on the order of $5600 \mathrm{~m}$ was located directly east of the main higher height value. Of particular interest, however, is to note that this trough remained quasistationary over the Gulf of Alaska while the ridge amplified (see Figure 3(b) - the $5750 \mathrm{~m}$ contour was located over Alaska following the period from Figure 3(a)). This feature appeared to be the central focus for action in the blocking region. The four days beginning on 10 August 2004 show the lower height responsible for the split-flow block deepened as the blocking intensified, as did the ridge (Figure 3(b)). The last several days of the period showed this feature propagating over the Alaskan Peninsula as the new ridge amplified over the Bering Sea upstream of the dying event. The block became fully suppressed by 27 August as the mean $500 \mathrm{hPa}$ height field became nearly zonal in character (Figure 3(c)).

4.2. Scale Analysis. Figure 4(a) displays the $500 \mathrm{hPa}$ blocking area averaged planetary-scale height for the entire life-cycle of the block. During the mature stage of the block life-cycle, the height attains its relative maximum value $(5778 \mathrm{~m})$. Note the occurrence of a positive height during the mature stage (05-20 August 2004) of the blocking as the monthly mean value for the entire month of August lies at $5748 \mathrm{~m}$ only. The average heights within the box start falling until just before the block decay (day number 21). This suggests changes in the behavior of the planetary-scale flow regime.

Figure 4(b) displays the $500 \mathrm{hPa}$ synoptic-scale height for the entire life-cycle of the selected blocking event. During the decay stage (20-28 August), the temporal activity of the migratory synoptic-scale heights is greater than during the onset and mature stages since during the decay stage, the synoptic-scale environment becomes unstable. The oscillatory behavior is indicative of area averaged synoptic-scale ridge-trough dominance for the advection of the heat wave at the given isobaric level. A positive difference corresponds to the high pressure system/ridge, whereas the negative difference corresponds to the formation of a trough.

This blocking event is the second longest blocking event in the east Pacific region for the calendar year 2004. This finding is in agreement with the estimates of longevity by [45]. This unusually prolonged blocking event impacted the downstream regional weather over the continental US as well. The west cost of the mainland continental US experienced mild summer during August 2004 [46]. This is yet another example of the occurrence of mid-tropospheric level blocking affecting the regional weather upstream and/or downstream of the event (e.g., [47]). For details of climatological aspects of downstream weather impacts associated with the blockings, see also [48].

4.3. Stability Analysis. Figure 5(a) displays the time evolution of the blocking area integrated regional enstrophy (IRE) for the $500 \mathrm{hPa}$ planetary-scale height. Comparing this with Figure 4(a) that gives the time evolution of the planetaryscale height, it is noted that between 21 and 23 August, the IRE increases considerably (peaking on 22 August), indicating the rise in the instability in the planetary-scale flow which corresponds well in time with the fall in the amplitude of the planetary-scale height during the same period.

Calculation of the IRE following (2) for entire life-cycle of the blocking event under study indicates a relationship between these values and the trend displayed in Figure 4(a), where blocking area averaged planetary-scale height is displayed. From Figure 5(a), it is noted that the area averaged enstrophy reaches a minimum shortly after block onset (after 
TABle 4: Planetary-scale and synoptic-scale dominance results for all the blocking events during the year 2002. The italic entries are the selected case studies. See text for details.

\begin{tabular}{|c|c|c|c|c|c|}
\hline Event no. & Start date & End date & Duration (days) & Planetary-scale dominance & Synoptic-scale dominance \\
\hline 1 & 02 Jan. & $11 \mathrm{Jan}$. & 9.5 & Positive & Negative \\
\hline 2 & 03 Jan. & 08 Jan. & 5 & Positive & Negative \\
\hline 3 & 07 Jan. & $28 \mathrm{Jan}$. & 21 & Alternating & Alternating \\
\hline 4 & 13 Jan. & 27 Jan. & 14 & Negative & Positive \\
\hline 5 & 25 Jan. & 30 Jan. & 5 & Negative & Positive \\
\hline 6 & 30 Jan. & 05 Feb. & 6 & Negative & Positive \\
\hline 7 & 31 Jan. & 06 Feb. & 5.5 & Negative & Positive \\
\hline 8 & 06 Feb. & $11 \mathrm{Feb}$. & 5 & Alternating & Alternating \\
\hline 9 & 02 Feb. & $12 \mathrm{Feb}$. & 10 & Negative & Positive \\
\hline 10 & 12 Feb. & 17 Feb. & 5 & Negative & Positive \\
\hline 11 & 11 Feb. & 28 Feb. & 17 & Alternating & Alternating \\
\hline 12 & 01 Mar. & 07 Mar. & 6 & Positive & Negative \\
\hline 13 & 04 Mar. & 21 Mar. & 17 & Negative & Positive \\
\hline 14 & 06 Mar. & 21 Mar. & 15 & Positive & Negative \\
\hline 15 & 09 Mar. & 28 Mar. & 19 & Negative & Positive \\
\hline 16 & 01 Apr. & 18 Apr. & 17 & Positive & Negative \\
\hline 17 & 02 Apr. & 07 Apr. & 5 & Negative & Positive \\
\hline 18 & 15 Apr. & 24 Apr. & 9 & Positive & Negative \\
\hline 19 & 19 Apr. & 04 May & 13.5 & Negative & Positive \\
\hline 20 & 23 Apr. & 03 May & 8.5 & Negative & Positive \\
\hline 21 & 10 May & 19 May & 9 & Positive & Negative \\
\hline 22 & 09 May & 29 May & 20 & Positive & Negative \\
\hline 23 & 01 Jun. & 10 Jun. & 9 & Alternating & Alternating \\
\hline 24 & 04 Jun. & 09 Jul. & 35 & Alternating & Alternating \\
\hline 25 & 22 Jun. & 30 Jun. & 8 & Negative & Positive \\
\hline 26 & 30 Jun. & 08 Jul. & 9 & Positive & Negative \\
\hline 27 & 06 Jul. & 17 Jul. & 9 & Negative & Positive \\
\hline 28 & $30 \mathrm{Jul}$. & 07 Aug. & 8 & Positive & Negative \\
\hline 29 & 01 Aug. & 11 Aug. & 10 & Positive & Negative \\
\hline 30 & 15 Aug. & 28 Aug. & 13 & Negative & Positive \\
\hline 31 & 07 Sep. & 18 Sep. & 11 & Alternating & Alternating \\
\hline 32 & 23 Sep. & 28 Sep. & 5 & Positive & Negative \\
\hline 33 & 20 Sep. & 02 Oct. & 12 & Positive & Negative \\
\hline 34 & 06 Oct. & 15 Oct. & 9 & Positive & Negative \\
\hline 35 & 13 Oct. & 18 Oct. & 5 & Alternating & Alternating \\
\hline 36 & 22 Oct. & 03 Nov. & 12 & Negative & Positive \\
\hline 37 & 25 Oct. & 30 Oct. & 5 & Negative & Positive \\
\hline 38 & 01 Nov. & 06 Nov. & 5.5 & Alternating & Alternating \\
\hline 39 & 18 Nov. & 25 Nov. & 7 & Positive & Negative \\
\hline 40 & 20 Nov. & 11 Dec. & 21 & Negative & Positive \\
\hline 41 & 26 Nov. & 28 Dec. & 32.5 & Alternating & Alternating \\
\hline
\end{tabular}

2 August) and is at a relative minimum during the mature stage of this blocking event. The appearance of relatively small peaks on 5 and 15 August indicate the decreasing role played by the planetary-scale heights in advection of the (quasi stationary) ridge in terms of its location and orientation. Inspection of series of $500 \mathrm{hPa}$ height plots (such as those displayed in Figure 3) for the chosen blocking event supports this observation. This is also consistent with the view that, in a quasibarotropic flow, the planetary-scale flow should be strongly barotropic [49]. Figure 5(a) indicates that after the onset of the blocking state, the block IRE attains relatively lower positive values.

The calculation for the IRE was also performed by taking into account the effects of synoptic-scale eddies and 
TABle 5: Same as Table 4 except for the year 2003.

\begin{tabular}{|c|c|c|c|c|c|}
\hline Event no. & Start date & End date & Duration (days) & Planetary-scale dominance & Synoptic-scale dominance \\
\hline 1 & 02 Jan. & 10 Jan. & 8 & Negative & Positive \\
\hline 2 & 12 Jan. & 18 Jan. & 6 & Positive & Negative \\
\hline 3 & 14 Jan. & 20 Jan. & 6 & Positive & Negative \\
\hline 4 & 23 Jan. & 06 Feb. & 14.5 & Alternating & Alternating \\
\hline 5 & 25 Jan. & 01 Feb. & 7 & Positive & Negative \\
\hline 6 & 09 Feb. & 15 Feb. & 6 & Alternating & Alternating \\
\hline 7 & 09 Feb. & 22 Feb. & 13 & Positive & Negative \\
\hline 8 & 20 Feb. & 02 Mar. & 11 & Negative & Positive \\
\hline 9 & 20 Feb. & 26 Feb. & 6 & Negative & Positive \\
\hline 10 & 07 Mar. & 18 Mar. & 10.5 & Positive & Negative \\
\hline 11 & 19 Mar. & 25 Mar. & 6 & Negative & Positive \\
\hline 12 & 29 Mar. & 08 Apr. & 9.5 & Negative & Positive \\
\hline 13 & 04 Apr. & 13 Apr. & 9 & Negative & Positive \\
\hline 14 & 14 Apr. & 22 Apr. & 8.5 & Positive & Negative \\
\hline 15 & 26 Apr. & 06 May & 10 & Negative & Positive \\
\hline 16 & 01 May & 22 May & 21 & Alternating & Alternating \\
\hline 17 & 12 May & 23 May & 11 & Positive & Negative \\
\hline 18 & 13 May & 28 May & 15 & Alternating & Alternating \\
\hline 19 & 25 May & 12 Jun. & 17 & Positive & Negative \\
\hline 20 & 03 Jun. & 12 Jun. & 9 & Negative & Positive \\
\hline 21 & 04 Jun. & 22 Jun. & 18.5 & Negative & Positive \\
\hline 22 & 13 Jun. & 24 Jun. & 11 & Positive & Negative \\
\hline 23 & 24 Jun. & $05 \mathrm{Jul}$. & 11 & Positive & Negative \\
\hline 24 & 28 Jun. & 07 Jul. & 9 & Alternating & Alternating \\
\hline 25 & 09 Jul. & 10 Aug. & 32 & Positive & Negative \\
\hline 26 & 11 Jul. & 19 Jul. & 7.5 & Alternating & Alternating \\
\hline 27 & $18 \mathrm{Jul}$. & 05 Aug. & 18 & Positive & Negative \\
\hline 28 & 06 Aug. & 13 Aug. & 7 & Alternating & Alternating \\
\hline 29 & 12 Aug. & 26 Aug. & 14 & Alternating & Alternating \\
\hline 30 & 24 Aug. & 13 Sep. & 21.5 & Alternating & Alternating \\
\hline 31 & 01 Sep. & 10 Sep. & 9 & Positive & Negative \\
\hline 32 & 10 Sep. & 20 Sep. & 10 & Positive & Negative \\
\hline 33 & 11 Sep. & 20 Sep. & 9 & Positive & Negative \\
\hline 34 & 13 Sep. & 25 Sep. & 12 & Negative & Positive \\
\hline 35 & 24 Sep. & 10 Oct. & 16 & Alternating & Alternating \\
\hline 36 & 25 Aug. & 07 Sep. & 12 & Alternating & Alternating \\
\hline 37 & 28 Sep. & 05 Oct. & 7 & Positive & Negative \\
\hline 38 & 28 Sep. & 05 Oct. & 7 & Alternating & Alternating \\
\hline 39 & 13 Oct. & 24 Oct. & 11 & Negative & Positive \\
\hline 40 & 29 Oct. & 08 Nov. & 9.5 & Positive & Negative \\
\hline 41 & 01 Nov. & 06 Nov. & 5 & Positive & Negative \\
\hline 42 & 05 Nov. & 16 Nov. & 11 & Positive & Negative \\
\hline 43 & 27 Oct. & 04 Nov. & 7 & Alternating & Alternating \\
\hline 44 & 04 Dec. & $10 \mathrm{Dec}$. & 6.5 & Alternating & Alternating \\
\hline 45 & 16 Dec. & 21 Dec. & 5 & Positive & Negative \\
\hline 46 & 19 Dec. & 26 Dec. & 7 & Positive & Negative \\
\hline 47 & 28 Nov. & 05 Dec. & 8 & Positive & Negative \\
\hline 48 & 29 Nov. & 04 Dec. & 6 & Alternating & Alternating \\
\hline
\end{tabular}


Table 6: Same as Table 5 except for the year 2004.

\begin{tabular}{|c|c|c|c|c|c|}
\hline Event no. & Start date & End date & Duration (days) & Planetary-scale dominance & Synoptic-scale dominance \\
\hline 1 & 27 Dec. & 09 Jan. & 13 & Positive & Negative \\
\hline 2 & 02 Jan. & 11 Jan. & 9.5 & Negative & Positive \\
\hline 3 & 23 Jan. & 05 Feb. & 13 & Negative & Positive \\
\hline 4 & 18 Jan. & 18 Feb. & 31 & Positive & Negative \\
\hline 5 & 10 Feb. & 14 Mar. & 31.5 & Alternating & Alternating \\
\hline 6 & 14 Feb. & 28 Feb. & 14 & Negative & Positive \\
\hline 7 & 28 Feb. & 05 Mar. & 5 & Alternating & Alternating \\
\hline 8 & 15 Mar. & 20 Mar. & 5 & Negative & Positive \\
\hline 9 & 17 Mar. & 22 Mar. & 5 & Negative & Positive \\
\hline 10 & 22 Mar. & 29 Mar. & 7.5 & Negative & Positive \\
\hline 11 & 26 Mar. & 12 Apr. & 17 & Negative & Positive \\
\hline 12 & 11 Apr. & 16 Apr. & 5 & Negative & Positive \\
\hline 13 & 14 Apr. & 22 Apr. & 7.5 & Positive & Negative \\
\hline 14 & 16 Apr. & 26 Apr. & 10 & Positive & Negative \\
\hline 15 & 20 Apr. & 13 May & 23 & Alternating & Alternating \\
\hline 16 & 06 May & 13 May & 7.5 & Negative & Positive \\
\hline 17 & 10 May & 25 May & 15.5 & Positive & Negative \\
\hline 18 & 12 May & 01 Jun. & 20 & Negative & Positive \\
\hline 19 & 05 Jun. & 10 Jun. & 5 & Negative & Positive \\
\hline 20 & 26 Jun. & $10 \mathrm{Jul}$. & 14 & Positive & Negative \\
\hline 21 & $02 \mathrm{Jul}$. & 13 Jul. & 10.5 & Negative & Positive \\
\hline 22 & 06 Jul. & $11 \mathrm{Jul}$. & 5 & Negative & Positive \\
\hline 23 & 12 Jul. & 24 Jul. & 11.5 & Positive & Negative \\
\hline 24 & 27 Jul. & 01 Aug. & 5 & Positive & Negative \\
\hline 25 & 27 Jul. & 15 Aug. & 18.5 & Positive & Negative \\
\hline 26 & 05 Aug. & 28 Aug. & 23.5 & Positive & Negative \\
\hline 27 & 09 Aug. & 15 Aug. & 6.5 & Positive & Negative \\
\hline 28 & 06 Sep. & 11 Sep. & 5 & Negative & Positive \\
\hline 29 & 08 Oct. & 15 Oct. & 7 & Positive & Negative \\
\hline 30 & 12 Oct. & 26 Oct. & 14 & Negative & Positive \\
\hline 31 & 18 Oct. & 28 Oct. & 10 & Negative & Positive \\
\hline 32 & 02 Nov. & 13 Nov. & 11 & Positive & Negative \\
\hline 33 & 04 Nov. & 26 Nov. & 22 & Positive & Negative \\
\hline 34 & 21 Nov. & 26 Nov. & 5 & Positive & Negative \\
\hline 35 & 09 Dec. & 14 Dec. & 5 & Positive & Negative \\
\hline 36 & 19 Dec. & 25 Dec. & 6 & Positive & Negative \\
\hline 37 & 19 Dec. & 26 Dec. & 7 & Negative & Positive \\
\hline
\end{tabular}

is displayed in Figure 5(b). At mid tropospheric level, the synoptic-scale IRE does not exhibit a clear trend in any of the three stages of blocking. The only trend that is obvious is that near the onset (after day 5), the IRE attains a relatively lower value, thus characterizing the relative stability of the flow at the synoptic-scale. The IRE gives a relative change only and is thus alone not sufficient to identify the blocking event unambiguously.

The temporal behavior of another stability indicator is displayed in Figure 6(a) for the blocking area averaged planetary-scale height. As mentioned in Section 2.4, $\psi$ acquires a relative maximum value, above the corresponding monthly mean, during the blocking state and is similar to the time evolution of the average planetary-scale height displayed in Figure 4(a). Following [30], it may be concluded that if $\max |\nabla \psi|$ depicts relatively positive changes, then the height variation is becoming increasingly unstable. Figure 6(a) indicates that the planetary-scale flow remains largely stable during the blocking since the relative positive variation implied by $\max |\nabla \psi|$ is less than $0.2 \%$, when averaged over the blocking life-cycle.

Figure 6(b) is similar to Figure 6(a) except that now we make use of the synoptic-scale height to calculate the $\max |\nabla \psi|$. The appearance of the relatively sharp rise during the decay stage, above the corresponding monthly mean value, is consistently explainable in our picture of the relative 
role of the two scales. The planetary-scale flow is more stable during the blocking; the synoptic-scale ridge formation destabilizes it thus causing the flow to revert back to the zonal configuration. This implies that once the blocking event established itself, the planetary-scale flow is relatively more predictable in the present case study.

4.4. Discussion. Changes in the nature of the planetaryscale flow may be related with the block onset and decay $[15,24,25,50]$. The planetary-scale provides a favorable environment for the blocking event to occur, in spite of the large contributions by the synoptic-scale flow and the interaction components of the forcing.

The supporting evidence for the change in planetaryscale flow regimes comes from examining the IRE (flow stability) calculations. The IRE values (Figure 5(a)) fall to a relative minimum during the mature stage of the block in the blocked region in agreement with what would be expected for the selected blocking event (with planetary-scale dominance) implying that the planetary-scale flow became unstable around the time of the block onset and decay.

Further, the prominence of the synoptic-scale in winter events versus the planetary-scale prominence in the summer events follows from the annual variation in the number and strength of midlatitude cyclones. It also follows that most of the studies referenced above [9, 11, 12], studied winter season events, and as such focused on the contribution of the synoptic-scale in the blocking events. On the other hand, even though summer season events were dominated by the planetary-scale, the forcing itself may still be dominated by the synoptic-scale as was found by [14], or it is possible that this study chose an event represented by the minority of warm season types. This fact points to the need for more case studies of the blocking events.

\section{Summary and Conclusions}

In this section, the findings for the three-year scale contributions study are summarized first, and then results for the case study are presented. The scale analysis is performed by decomposing the observed $500 \mathrm{hPa}$ height into the blocking area averaged planetary-scale and the synoptic-scale heights and then the time evolution of both the contributions is analyzed during the life-cycle for the entire set of the blocking events.

Using the NCEP-NCAR gridded reanalyzed data for 2002-2004, and averaging over the $40^{\circ} \times 60^{\circ}$ latitude longitude box encompassing the blocking event and based on our criterion of scale dominance as a height value above the monthly mean value for that height during the month in which the blocking occurs, the findings may be summarized as follows.

(i) A total of 126 events were analyzed to determine the scale contribution dominance of the planetary- and synoptic-scales during the blocking of the zonal flow. $79 \%$ of the total analyzed events have single height dominance. Out of these, $44 \%$ have planetary-scale dominance whereas 35\% have synoptic-scale dominance in scale contributions. The remaining $21 \%$ of the blocking events are categorized as alternatingheight scale dominance blocking events. Blocking events from December to May (June-November) were more synoptic (planetary) scale dominant.

(ii) The sensitivity of our results to the blocking domain size variation was studied. When the blocking domain size was varied from $40^{\circ} \times 60^{\circ}$ to $80^{\circ} \times$ $100^{\circ}$, the deviation of the planetary-scale height that is averaged over it was found to be less than $1 \%$. This indicates that our conclusions are relatively insensitive to the blocking domain size variation for the planetary-scale height within the above latitude and longitude range.

Next, summary of the synoptic analysis as well as the scale and the stability analysis of an unusually prolonged and a moderately strong blocking event occurring in the Gulf of Alaska during August 2004, is presented. This blocking event persisted in Gulf of Alaska for the entire month of August resulting in a heat wave (up to $5^{\circ} \mathrm{C}$ higher than normal 19712000 mean temperatures in Alaska region). Our analyzed results are as follows.

(i) A synoptic study of this event was performed through visual inspection of a series of NCEP-NCAR reanalysis data generated plots of observed $500 \mathrm{hPa}$ heights and was concluded that the blocking is a positive height anomaly encompassing $40^{\circ} \mathrm{N}-80^{\circ} \mathrm{N}$ and $160^{\circ} \mathrm{E}-260^{\circ} \mathrm{E}$. The detailed scale contribution analyses, performed using explicit calculations, for the specific case study, confirm this. This positive comparison lends confidence in our diagnostic analysis procedure outlined in Section 2.

(ii) Synoptically, a gradual amplification of positive height value during the first half of the blocking event life-cycle (5-15 August 2004) and then later a deamplification during later half of the blocking event life-cycle (15-28 August 2004) based on same observational procedure, was noticed. Our Figure 4(a) confirms this finding.

(iii) Subtracting the planetary mean from the total pressure plots indicates that the synoptic-scale eddies did not play leading role in this event. Furthermore, through the same analysis, it is noted that planetaryscale is more stable. The relative stability role of the two scales under the working assumption of the Dymnikov conjecture (see Appendix A) was analyzed that confirms this finding. This was the first time this conjecture has been used for an observational case study.

(iv) It is noted that meridional gradient of the planetaryscale height field exists at mid-tropospheric level through visual inspection. Our results displayed in Figure 6(a) confirm this finding. This in turn provides support for using simple variable such as $\max |\nabla \psi|$ as a possible stability indicator of the flow. 
(v) These two diagnostic tools show that the planetaryscale environment becomes unstable during the onset and then stabilizes during the mature stage of the blocking whereas the synoptic-scale heights play a dominant role in destabilizing the planetary-scale flow during the mature stage of the blocking life-cycle initiating the blocking decay. The interplay of both the contributions is found to be the case during the three stages of the blocking, when their relative role is assessed in terms of the IRE and the maximum of the gradient of the flow stream function.

It can be pointed out, that this study also confirms the tentative conclusions of earlier studies that both the planetary- and synoptic-scales are equally important in the life-cycle of the blockings in the midlatitude NH zonal flow in general (see Section 1 for references). Based on the threeyear study, the above observations are true irrespective of whether the blocking event occurs entirely over the land, over the ocean, or partially over the land and partially over the ocean. This may indicate more dominating role played by the different scales and their interactions in the flow once the blocking sets in instead of orographic forcings.

As exemplified by the selected case study, the IRE may characterize the stability of the planetary/synoptic-scale flow in the barotropic circulation. A simultaneous knowledge of the two diagnostic tools, however, seems to provide a more reliable scenario for the occurrence, sustenance as well as decay of a blocking event. The IRE of the Dymnikov conjecture gives only the relative stability of the flow. Height variations alone however do not provide any underlying insight into the scale contributions and the flow stability during the blocking period. A simultaneous estimate of both may establish the presence and the stability behavior of the flow. The above observations made in this study find some justification in light of the previous studies mentioned in Section 1, where it was concluded that both the planetaryscale as well as the synoptic-scale heights seems to play some role in essentially all stages of the blocking life-cycle. Though depending upon the specific case study, the relative strength of the role seems to vary.

\section{Appendices}

\section{A. Area Integrated Regional Enstrophy}

The dynamic equation of viscous incompressible barotropic fluid for the stream function $\psi$ is given by

$$
\frac{\partial \Delta \psi}{\partial t}+J(\psi, \Delta \psi)=0
$$

The $\Delta$ is the Laplacian operator. The $J$ is the Jacobian incorporating the nonlinear interactions. Expanding $\psi$ in terms of time-dependent and time-independent components, respectively, such that $\psi=\psi^{\prime}+\bar{\psi}$, where $\psi^{\prime}=$ $\psi^{\prime}(t)$ and $\bar{\psi} \neq \bar{\psi}(t)$. The equation of motion for linearization operator $L$ is $\partial \Delta \psi^{\prime} / \partial t+L \psi^{\prime}=0$, where

$$
L \psi^{\prime}=J\left(\psi^{\prime}, \Delta \bar{\psi}\right)+J\left(\bar{\psi}, \Delta \psi^{\prime}\right) .
$$

The perturbation energy equation in terms of scalar product $\left(L \psi^{\prime}, \psi^{\prime}\right)$ is

$$
\frac{\partial E^{\prime}}{\partial t}=\left(L \psi^{\prime}, \psi^{\prime}\right)
$$

Since $L=S+K$, where $K$ is the skew-symmetric part of the operator $L$ and $S$ is the symmetric part of the operator $L$, the perturbation energy equation may be rewritten with $L \rightarrow S$ in (A.3), that is

$$
\frac{\partial E^{\prime}}{\partial t}=\left(S \psi^{\prime}, \psi^{\prime}\right)
$$

Note that the stationary solution $\bar{\psi}$ will be stable if all the eigenvalues of the operator $S$ with respect to stationary solution are negative. We shall thus take the sum of positive eigenvalues of the operator $S$ as the characteristics of the instability of the stationary point.

Assuming that $\bar{\psi}=\bar{\psi}(y)$; that is, the stationary solution does not depend on zonal coordinate to mimic meridionally directed perturbation (namely, the blocking) in the mainly zonal flow and using the periodic conditions for $x$ and $y$ and passing to finite dimensions, after some algebraic manipulation, the eigenvalue problem for the operator $S$ (where $2 S=L+L^{*}$ ) has the form

$$
\bar{u} \frac{\partial}{\partial x} \Delta \tilde{\varphi}-\Delta\left(\bar{u} \frac{\partial \tilde{\varphi}}{\partial x}\right)=\lambda \tilde{\varphi} .
$$

Here, $\lambda$ 's are the eigenvalues of the eigenoperator $\tilde{\varphi}$. The $\lambda$ 's play the role of the characteristic exponents. We shall look for the general solution of (A.5) in the form that depends on $x$ and $y: \tilde{\varphi}(x, y)=\tilde{\varphi}(y) e^{i k x}$. With this transformation, we obtain the following eigenvalue equation from (A.5)

$$
\begin{gathered}
\frac{\partial \bar{\varsigma} \tilde{\varphi}}{\partial y}+\bar{\varsigma} \frac{\partial \tilde{\varphi}}{\partial y}=\frac{\lambda}{i k} \widetilde{\varphi}, \\
\bar{\varsigma}=-\frac{\partial \bar{u}}{\partial y} .
\end{gathered}
$$

In principle, one should solve this equation to obtain the spectrum of eigenvalues $\lambda$, which depends upon $\bar{\zeta}$. Note $\bar{\varsigma}$ is the vertical component of the relative vorticity for the stationary component of the stream function. Here, we make use of the Dymnikov et al. [29] conjecture which suggests a strong correlation between the sum of the positive characteristic exponents (eigenvalues of the linearization operator of barotropic flow) and the (blocked) domain integrated enstrophy, that is

$$
\sum_{i} \lambda_{i}^{+} \approx \int_{D}|\bar{\varsigma}|^{2}(y) d x d y .
$$

Equation (A7) can be obtained from (A.6) by first writing (A.6) in finite difference form and then using a known algebraic relation. This is the same as (2) in Section 2.3 of the text, with $\bar{\varsigma} \rightarrow \varsigma$. Let us add that a numerical implementation of equation for $L$ via Crank-Nicholson scheme in [29] using data for a three-year period after applying a 15-day filter 
(planetary-scale) on domains $D$ over the north Atlantic and western Europe establishes the validity of (A.7).

Summarizing, to the extent that the average time for $\bar{\varsigma}$ trajectories to diverge decreases as the sum of the positive characteristic exponent's increases, we get a preliminary indication of how physical quantities, such as enstrophy, may be viewed as forecasting indicators. The time evolution of right hand side of (A.7) may thus represent the relative stability of the barotropic flow. Development of a mainly meridional perturbation ( $y$ dependence only of $\psi$ ) signifies relative stability of the flow which we interpret as the blocking under the working assumption of Dymnikov et al. conjecture [29]. Note that right hand side of (A.7) refers to area averaged (relative) vorticity squared as mentioned earlier.

\section{B. The Blocking Height-Scale Contribution Analysis for 2002-2004}

See Tables 4, 5, and 6 .

\section{Acknowledgments}

The authors thank Dr. Courtenay Strong for helpful discussions during the early stages of this work. The authors also thank Dr. Mansour Almazroui for his continuous support and cooperation.

\section{References}

[1] D. Rex, "Blocking action in the middle troposphere and its effect upon regional climate I. An aerological study of blocking action," Tellus, vol. 2, pp. 196-211, 1950.

[2] D. Rex, "Blocking action in the middle troposphere and its effect upon regional climate II. The climatology of blocking action," Tellus, vol. 2, pp. 275-301, 1950.

[3] R. Benzi, B. Saltzman, and A. C. Wiin-Nielsen, Anomalous Atmospheric Flows and Blocking, vol. 29 of Advances in Geophysics, Academic Press, Boston, Mass, USA, 1986.

[4] J. S. Watson and S. J. Colucci, "Evaluation of ensemble predictions of blocking in the NCEP global spectral model," Monthly Weather Review, vol. 130, no. 12, pp. 3008-3021, 2002.

[5] J. G. Charney and J. G. Devore, "Multiple flow equilibria in the atmosphere and blocking," Journal of the Atmospheric Sciences, vol. 36, no. 7, pp. 1205-1216, 1979.

[6] G. J. Shutts, "The propagation of eddies in diffluent jetstreams: eddy vorticity forcing of ' blocking' flow fields," Quarterly Journal of the Royal Meteorological Society, vol. 109, no. 462, pp. 737-761, 1983.

[7] D. Luo, A. R. Lupo, and H. Wan, "Dynamics of eddy-driven low-frequency dipole modes. Part I: a simple model of North Atlantic Oscillations," Journal of the Atmospheric Sciences, vol. 64, no. 1, pp. 3-28, 2007.

[8] D. Luo, T. T. Gong, and A. R. Lupo, "Dynamics of eddy-driven low-frequency dipole modes. Part II: free mode characteristics of NAO and diagnostic study," Journal of the Atmospheric Sciences, vol. 64, no. 1, pp. 29-51, 2007.

[9] M. S. Tracton, "Predictability and its relationship to scale interaction processes in blocking," Monthly Weather Review, vol. 118 , no. 8, pp. 1666-1695, 1990.
[10] H. Nakamura and J. M. Wallace, "Observed changes in baroclinic wave activity during the life cycles of low-frequency circulation anomalies," Journal of the Atmospheric Sciences, vol. 47, no. 9, pp. 1100-1116, 1990.

[11] A. R. Lupo and P. J. Smith, "Planetary and synoptic-scale interactions during the life cycle of a midlatitude blocking anticyclone over the North Atlantic," Tellus, vol. 47, no. 1, pp. 575-596, 1995.

[12] A. R. Lupo, "A diagnosis of two blocking events that occurred simultaneously in the midlatitude Northern Hemisphere," Monthly Weather Review, vol. 125, no. 8, pp. 1801-1823, 1997.

[13] H. Nakamura, M. Nakamura, and J. L. Anderson, "The role of high- and low-frequency dynamics in blocking formation," Monthly Weather Review, vol. 125, no. 9, pp. 2074-2093, 1997.

[14] A. R. Lupo and P. J. Smith, "The interactions between a midlatitude blocking anticyclone and synoptic-scale cyclones that occurred during the summer season," Monthly Weather Review, vol. 126, no. 2, pp. 503-515, 1998.

[15] J. P. Burkhardt and A. R. Lupo, "The planetary- and synopticscale interactions in a southeast Pacific blocking episode using PV diagnostics," Journal of the Atmospheric Sciences, vol. 62, no. 6, pp. 1901-1916, 2005.

[16] L. Dong and S. J. Colucci, "The role of deformation and potential vorticity in Southern Hemisphere blocking onsets," Journal of the Atmospheric Sciences, vol. 62, no. 11, pp. 40434056, 2005.

[17] L. Dong and S. J. Colucci, "Interpreting the opposition between two block-onset forcing mechanisms," Journal of the Atmospheric Sciences, vol. 64, no. 6, pp. 2091-2104, 2007.

[18] R. F. C. Marques and V. B. Rao, "A diagnosis of a long-lasting blocking event over the southeast Pacific Ocean," Monthly Weather Review, vol. 127, no. 8, pp. 1761-1776, 1999.

[19] A. R. Lupo, I. I. Mokhov, S. Dostoglou, A. R. Kunz, and J. P. Burkhardt, "Assessment of the impact of the planetary scale on the decay of blocking and the use of phase diagrams and enstrophy as a diagnostic," Izvestiya. Atmospheric and Oceanic Physics, vol. 43, no. 1, pp. 45-51, 2007.

[20] E. Kalnay-Rivas and L.-O. Merkine, "A simple mechanism for blocking," Journal of the Atmospheric Sciences, vol. 38, no. 10, pp. 2077-2091, 1981.

[21] J. S. Frederiksen, "A unified three-dimensional instability theory of the onset of blocking and cyclogenesis," Journal of the Atmospheric Sciences, vol. 39, no. 5, pp. 969-982, 1982.

[22] S. L. Mullen, "The local balances of vorticity and heat for blocking anticyclones in a spectral general circulation model," Journal of the Atmospheric Sciences, vol. 43, no. 13, pp. 14061441, 1986.

[23] S. L. Mullen, "Transient eddy forcing of blocking flows," Journal of the Atmospheric Sciences, vol. 44, no. 1, pp. 3-22, 1987.

[24] K. Haines and A. J. Holland, "Vacillation cycles and blocking in a channel," Quarterly Journal of the Royal Meteorological Society, vol. 124, no. 547, pp. 873-895, 1998.

[25] S. J. Colucci and D. P. Baumhefner, "Numerical prediction of the onset of blocking: a case study with forecast ensembles," Monthly Weather Review, vol. 126, no. 3, pp. 773-784, 1998.

[26] D. E. Tilly, A. R. Lupo, C. J. Melick, and P. S. Market, "Calculated height tendencies in two southern hemisphere blocking and cyclone events: the contribution of diabatic heating to block intensification," Monthly Weather Review, vol. 136, no. 9, pp. 3568-3578, 2008.

[27] P. J. Roebber, "Planetary waves, cyclogenesis, and the irregular breakdown of zonal motion over the North Atlantic," Monthly Weather Review, vol. 137, pp. 3907-3917, 2009. 
[28] S. J. Colucci, "Planetary-scale preconditioning for the onset of blocking," Journal of the Atmospheric Sciences, vol. 58, no. 8, pp. 933-942, 2001.

[29] V. P. Dymnikov, Y. V. Kazantsev, and V. V. Kharin, "Information entropy and local Lyapunov exponents of barotropic atmospheric circulation," Izvestiya. Atmospheric and Oceanic Physics, vol. 28, no. 6, pp. 425-432, 1993.

[30] Y. N. Skiba, "On the spectral problem in the linear stability study of flows on a sphere," Journal of Mathematical Analysis and Applications, vol. 270, no. 1, pp. 165-180, 2002.

[31] E. Kalnay, M. Kanamitsu, R. Kistler et al., "The NCEP/NCAR 40-year reanalysis project," Bulletin of the American Meteorological Society, vol. 77, no. 3, pp. 437-471, 1996.

[32] R. Kistler, E. Kalnay, W. Collins et al., "The NCEP-NCAR 50year reanalysis: monthly means CD-ROM and documentation," Bulletin of the American Meteorological Society, vol. 82, no. 2, pp. 247-267, 2001.

[33] A. R. Lupo and P. J. Smith, "Climatological features of blocking anticyclones in the Northern Hemisphere," Tellus. Series A, vol. 47, no. 4, pp. 439-456, 1995.

[34] H. Lejenas and H. Okland, "Characteristics of Northern Hemisphere blocking as determined from a long time series of observational data," Tellus. Series A, vol. 35, no. 5, pp. 350$362,1983$.

[35] R. Shapiro, "Smoothing, filtering, and boundary effects," Reviews of Geophysics and Space Physics, vol. 8, no. 2, pp. 359387,1970 .

[36] A. R. Hansen, "Observational characteristics of atmospheric planetary waves with bimodal amplitude distributions," Advances in Geophysics, vol. 29, pp. 101-133, 1986.

[37] B. Farrell, "Developing disturbances in shear," Journal of the Atmospheric Sciences, vol. 44, no. 16, pp. 2191-2199, 1987.

[38] A. R. Lupo, J. V. Clark, A. M. Hendin, et al., "The global increase in blocking occurrences," in Proceedings of the 20th Conference on Global Climate Change, American Meteorological Society, New Orleans, La, USA, 2008.

[39] J. M. Wiedenmann, A. R. Lupo, I. I. Mokhov, and E. A. Tikhonova, "The climatology of blocking anticyclones for the Northern and Southern Hemispheres: block intensity as a diagnostic," Journal of Climate, vol. 15, no. 23, pp. 3459-3473, 2002.

[40] T. C. Peterson, M. O. Baringer, H. J. Diamond et al., "State of the climate in 2008," Bulletin of the American Meteorological Society, vol. 90, no. 8, pp. S1-S196, 2009.

[41] M. Croci-Maspoli, C. Schwierz, and H. C. Davies, "A multifaceted climatology of atmospheric blocking and its recent linear trend," Journal of Climate, vol. 20, no. 4, pp. 633-649, 2007.

[42] D. Luo and H. Wan, "Decadal variability of wintertime North Atlantic and Pacific blockings: a possible cause," Geophysical Research Letters, vol. 32, no. 23, Article ID L23810, 5 pages, 2005.

[43] J. R. Key and A. C. K. Chan, "Multidecadal global and regional trends in $1000 \mathrm{mb}$ and $500 \mathrm{mb}$ cyclone frequencies," Geophysical Research Letters, vol. 26, no. 14, pp. 2053-2056, 1999.

[44] Alaskan Climate Record Center, "Record breaking summer of 2004," http://climate.gi.alaska.edu/News/summer04.html.

[45] D. Barriopedro, R. García-Herrera, A. R. Lupo, and E. Hernández, "A climatology of Northern Hemisphere blocking," Journal of Climate, vol. 19, no. 6, pp. 1042-1063, 2006.

[46] J. M. Glisan, Two extreme cases of atmospheric blocking over Europe and North America, M.S. thesis, Department of
Soil, Environmental and Atmospheric Sciences, University of Missouri, Columbia, 2007.

[47] R. S. Quiroz, "The climate of the 1983-84 winter-a season of strong blocking and severe cold in North America," Monthly Weather Review, vol. 112, no. 9, pp. 1894-1912, 1984.

[48] M. L. Carrera, R. W. Higgins, and V. E. Kousky, "Downstream weather impacts associated with atmospheric blocking over the Northeast Pacific," Journal of Climate, vol. 17, no. 24, pp. 4823-4839, 2004.

[49] M. Ghil and S. Childress, Topics in Geophysical Fluid Dynamics: Atmospheric Dynamics, Dynamo Theory, and Climate Dynamics, Springer, Berlin, Germany, 1987.

[50] C. H. Tsou and P. J. Smith, "The role of synoptic/planetaryscale interactions during the development of a blocking anticyclone," Tellus. Series A, vol. 42, no. 1, pp. 174-193, 1990. 

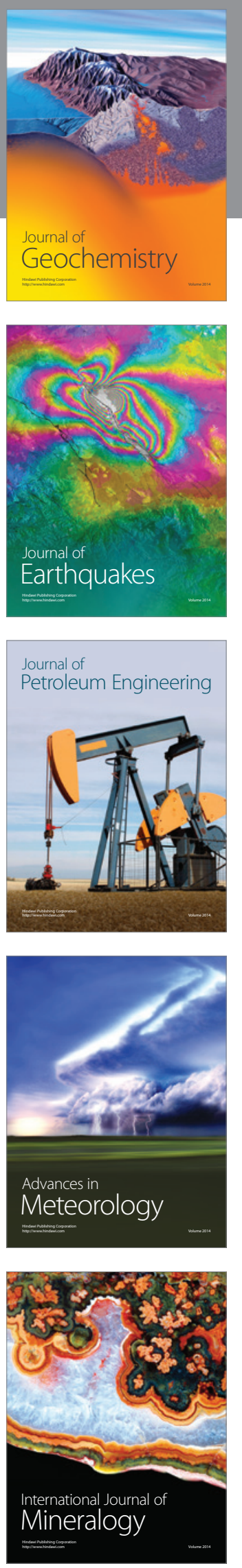
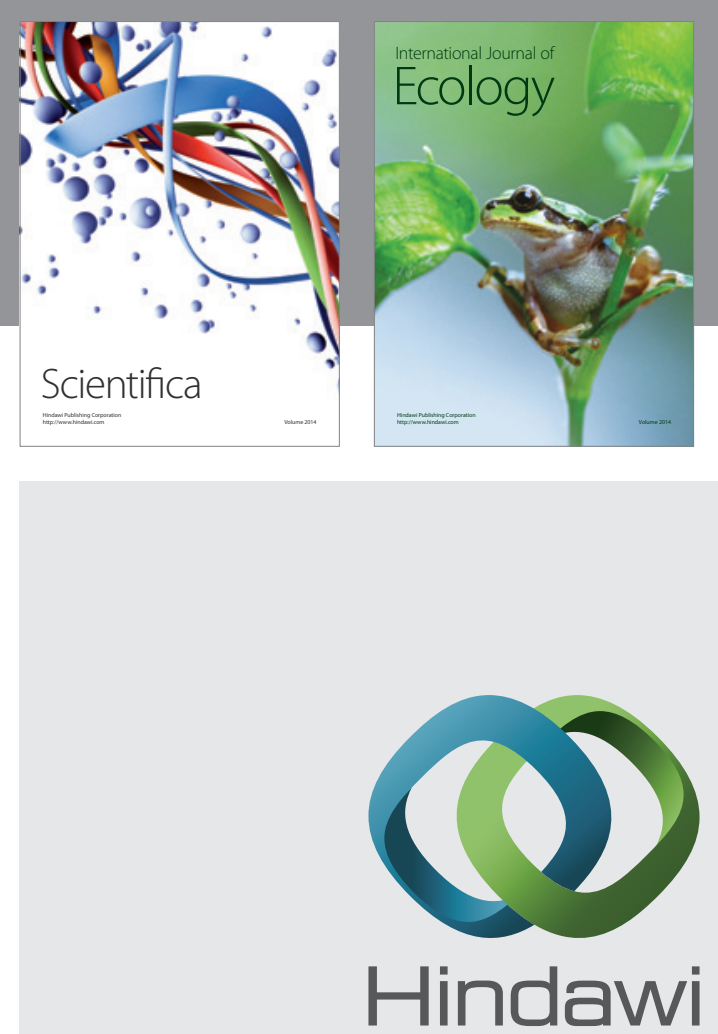

Submit your manuscripts at http://www.hindawi.com
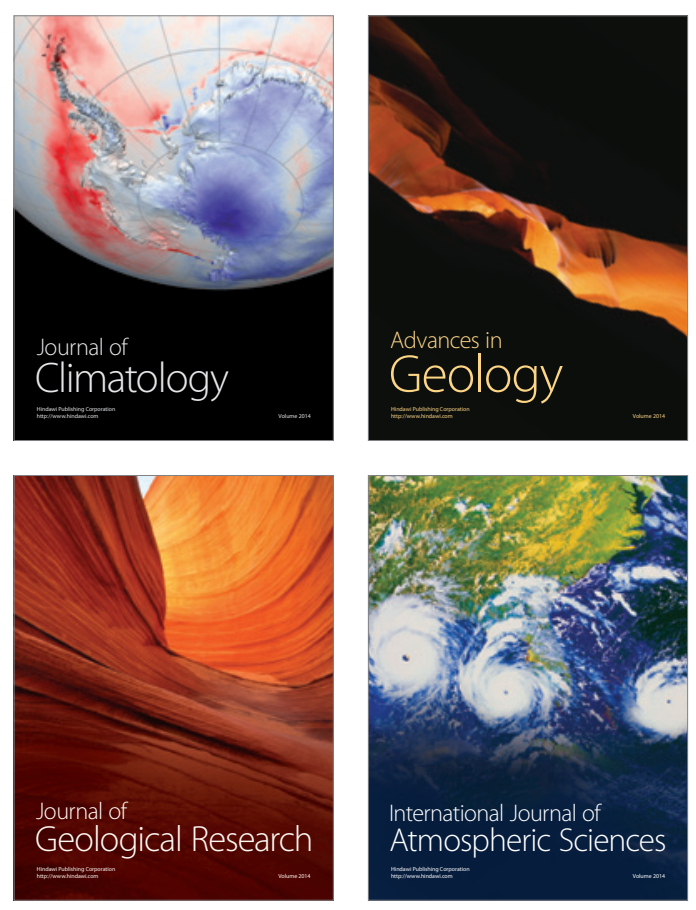
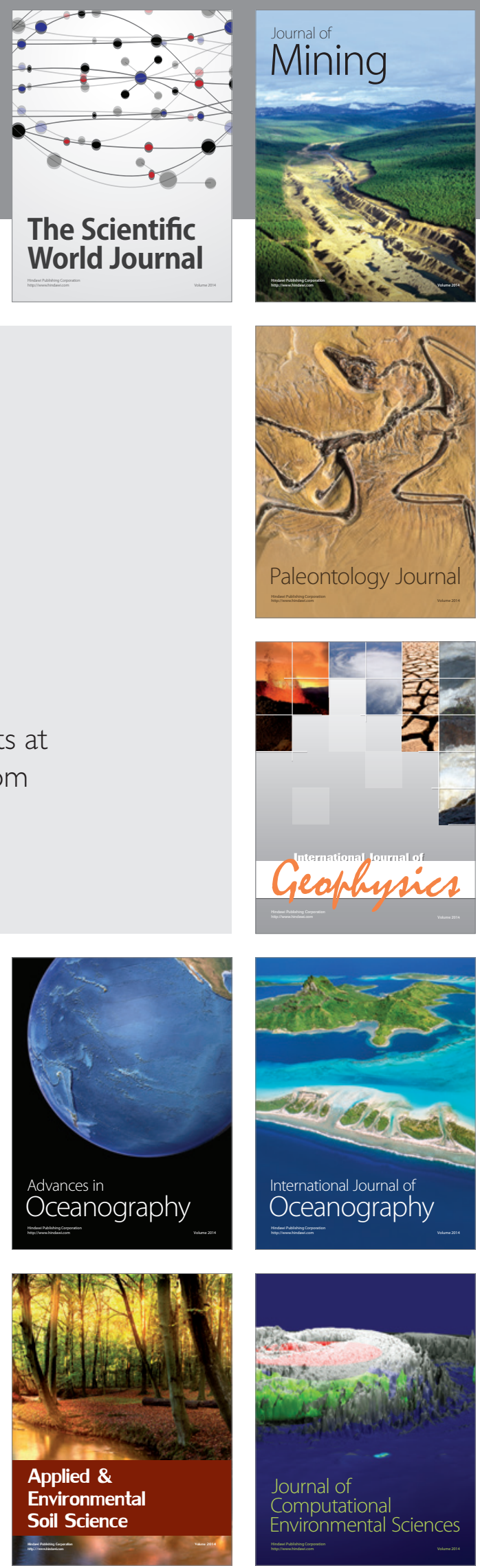